\title{
Flood routing in an ephemeral channel with compound cross-section
}

\author{
M BALAMURUGAN and S MURTY BHALLAMUDI*
}

Environmental and Water Resources Engineering Division, Department of Civil Engineering, Indian Institute of Technology Madras, Chennai 600 036, India

e-mail: bala.hwre@gmail.com; bsm@iitm.ac.in

MS received 10 August 2015; revised 23 November 2015; accepted 23 December 2015

\begin{abstract}
Natural phenomenon of surface and subsurface flow interaction is an intrinsic component of the hydrological processes in any watershed. It is a highly sensitive process, especially in arid and semi-arid regions, and should be considered while dealing with any water management activity in these regions. This paper describes a novel approach for flood routing in an ephemeral channel with compound cross-sections. The proposed mathematical model couples the numerical solution for complete Saint-Venant equations for surface flow with the numerical solution for one-dimensional Richards equation for sub-surface flow through an iterative procedure. Recently developed interactive divided channel (IDC) method is incorporated for simulating the main channel and flood plain flow interactions. In the one-dimensional surface and pseudo two-dimensional subsurface (1DSP2DSS) model presented here, the effect of lateral variation in infiltration rate at a cross section arising due to (i) lateral variation in flow depth and (ii) lateral variation in soil characteristics is incorporated by considering infiltration into different soil columns for main channel and flood plains. The proposed model is verified by comparing the model results with those available in literature for benchmark problems. Simulations are presented to demonstrate the capability of the model for flood routing in ephemeral channels with flood plains and the effect of lateral variation in infiltration rate on transmission losses.
\end{abstract}

Keywords. Flood routing; ephemeral channels; surface-subsurface interaction; compound channel; arid and semi-arid regions.

\section{Introduction}

The water balance in arid and semi-arid regions is quite different from other regions. Arid climatic conditions may favor high intensity rainfall for shorter durations which may result in quick runoff response and flash floods in ephemeral streams [1]. These stream beds are usually dry, resulting in the formation of very dry unsaturated zone. This will significantly influence the surface flow and recharge process by allowing high infiltration rate into the channel bed [2-5]. So most of the flood flows may simply disappear into the channel bed over some length of the channel. This flood loss into the channel bed is the most significant fraction of flood loss during channel conveyance [6-9] and forms an important source of groundwater recharge in arid and semi-arid regions $[1,10,11]$.

Movement of floods in ephemeral channels is strongly influenced by the infiltration into the ground, which in turn is affected by the movement of flood. Hence the accurate estimation of water balance or any water management activity in arid and semi-arid regions requires accurate numerical simulation of flood flow movement along with

*For correspondence channel transmission losses simultaneously. Predicting recharge into aquifers and maximizing the amount of recharge at desired locations in the aquifer requires knowledge of the spatial distribution of transmission losses along the channel, which in turn depend upon the correct simulation of flood flow movement [12-15]. Correctly predicting the time of arrival and travel distance of flood events is an essential component of making such predictions. The factors affecting channel transmission losses are (i) wetted channel width including flood plain, (ii) infiltration flux, (iii) stream flow duration and volume, (iv) geological characteristics and (v) channel evaporation and near channel transpiration [4, 10, 16-19]. The width of the channel plays an important role in determining transmission losses, as wider channels have greater total infiltration rates, which increase the potential for channel transmission losses [15, 20-23].

Flood routing in ephemeral streams has been studied by various researchers $[13,15,18,24-36]$ in the past. Many of these studies focused on estimating the recharge in ephemeral channels, finding the effect of rainfall-runoff in a dry channel, flood plain management for a particular river, protecting downstream cities and few more water management activities. Most of the researchers have not 
considered flood routing with full momentum equations. But in ephemeral channels, flood routing should be based on complete shallow water equation rather than diffusion wave or kinematic routing methods because it needs to deal with flash floods with higher order of magnitude. Numerically, shock capturing schemes should be employed in order to tackle numerical difficulties that may arise due to sharp fronts [15, 30]. Also, the surface flow equations for flood need to be coupled with unsaturated subsurface flow in the aquifer [37, 38]. However, only few researchers [18, 26, 31, 39, 40] focused on dynamic routing for flood flow simulation along with subsurface flow movement in arid region streams.

Most of the natural channels or rivers are composed of compound cross-sections [41, 42], which adds further complications to flood routing technique. The flow pattern is not simple even when a channel with well-defined flood plains is considered. Generally the flood plains have larger width and higher roughness as compared to the main channel. This impedes the flow and the flood plain velocities are much slower than the velocities in the main channel, which has less frictional resistance to the flow. Thus there exists a variation in velocity distribution across the cross section, and in turn there exists a variation in momentum across the section of a compound channel. This variation in momentum introduces lateral momentum transfer across the subdivisions of compound section, which results in acceleration of flow in flood plain and deceleration of flow in main channel. Although several two and three dimensional models are available in literature, one-dimensional models are still the most popular as far as flood routing in channels and rivers is concerned due to their reasonable accuracy from an engineering point of view, and their simplicity [43]. Flood routing in compound channel has been studied by several researchers in the past [41, 43-49]. However, these studies focused on improving the flood routing technique for compound channels by proper incorporation of the effect of momentum and mass exchange mechanisms between main channel and the floodplains. The focus was on evaluating the overall effect of flow resistance and lateral momentum transfer on conveyance, stage-discharge relationship and peak flow attenuation, etc. However, they did not consider the effect of infiltration on the flood movement.

A review of literature has indicated that several models are available for dynamic routing of flash floods in ephemeral channels with simple cross sections [15], where infiltration loss plays a significant role. Models are also available for flood routing in compound channels, but without infiltration [45]. However, to the authors' knowledge, models are not available for flood routing in ephemeral channels with compound cross-sections, although any water management activity in semi-arid/arid region requires more adequate knowledge on this issue. Presently available one-dimensional flood routing models for ephemeral channels do not consider the lateral variation in infiltration rate across a channel cross section, and so they cannot be applied for channels with compound crosssections. Therefore, the present research contribution consists of development of a model for flood routing in ephemeral channels with compound cross-sections. The proposed flood routing model solves the complete one-dimensional Saint-Venant equations for surface flow along with one-dimensional Richard's equation for unsaturated sub-surface flow. Surface and sub-surface flow components interact through the infiltration process at the ground surface. The infiltration rate which is obtained as a result of the subsurface flow acts as a link between the surface and subsurface systems. An iterative procedure is used for coupling the surface and sub-surface components. One-dimensional surface flow component is coupled with the subsurface flow component in such a way as to consider variation in infiltration rate across the wetted perimeter at any particular cross-section along the river length, based on (i) different arrival times for wetting front and (ii) surface flow depths. Results obtained using the proposed 1-D surface and pseudo 2-D sub-surface model are compared with those obtained using 1-D surface and 1-D subsurface flow model, for studying the effect of varying infiltration rate at a cross section, on the flood wave movement.

\section{Governing equations}

Flood routing in ephemeral channels involves numerical solution of governing partial differential equations for both surface flow and sub-surface flow, with infiltration acting as the connecting link. In the present study (figure 1), surface flow in the channel is assumed to be one-dimensional in the $X$-direction, while the sub-surface flow in the unsaturated porous medium is assumed to be one-dimensional in the $Z$ direction. In figure $1, \Delta Z$ is the space step in subsurface, $V_{u}$ and $V_{d}$ are the velocities at upstream and downstream faces of any subsurface node.

\subsection{Surface flow equations}

Surface flow is assumed to occur in a prismatic channel. It is assumed that shallow water flow conditions prevail and the Saint-Venant equations are applicable. These equations, which represent the continuity and the momentum equations, in conservation form are as follows:

$$
\begin{gathered}
\frac{\partial A}{\partial t}+\frac{\partial Q}{\partial x}+Q_{l}=0 \\
\frac{\partial Q}{\partial t}+\frac{\partial}{\partial x}\left(\frac{\beta Q^{2}}{A}+F_{p}\right)=g A\left(S_{0}-S_{f}\right),
\end{gathered}
$$

where $A=$ flow cross sectional area $\left(\mathrm{m}^{2}\right) ; Q=$ discharge $\left(\mathrm{m}^{3} / \mathrm{s}\right) ; g=$ acceleration due to gravity $\left(\mathrm{m} / \mathrm{s}^{2}\right) ; Q_{l}=$ volumetric infiltration rate per unit length $\left(\mathrm{m}^{2} / \mathrm{s}\right)$; 

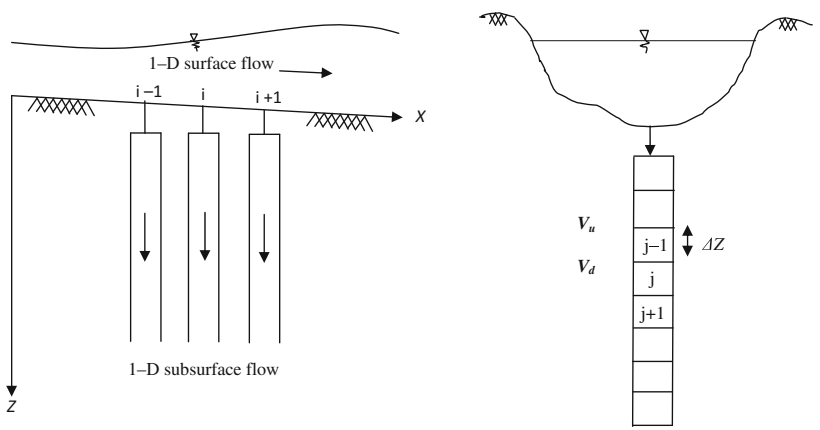

Figure 1. Definition sketch for flow model.

$\beta=$ momentum correction factor; $S_{o}=$ bottom slope in the direction of flow; $S_{f}=$ friction slope; $t=$ time (s) and $x=$ distance along the flow direction (m). In Eq. (2), term $F_{p}$ represents the net pressure force and is given by

$$
F_{p}=\int_{0}^{h} g * b(y) *(h-y) \mathrm{d} y,
$$

where $b(y)=$ width of channel at any height $y$ above the bottom and $h=$ flow depth. Assumptions underlying these equations are discussed elsewhere and are not repeated here. It may be noted here that the momentum associated with the infiltrating water is assumed to be insignificant. However, this effect can be considered easily as given in Mudd [15].

Present study focuses on flood routing in ephemeral channels having a compound cross-section. Based on the equations used for momentum correction factor, $\beta$ and the slope of the energy grade line, $S_{f}$, flood routing models for compound channels can be broadly classified into non-interacting divided channel (NIDC) and interacting divided channel (IDC) methods. Several of the existing methods for flood routing in compound channel do not consider any interaction between the flood plain and the main channel flows [43, 48]. In the non-interacting method, compound channel is divided into several sub-sections (figure 2), and each sub-section is treated as single channel, where $B_{m}$ is

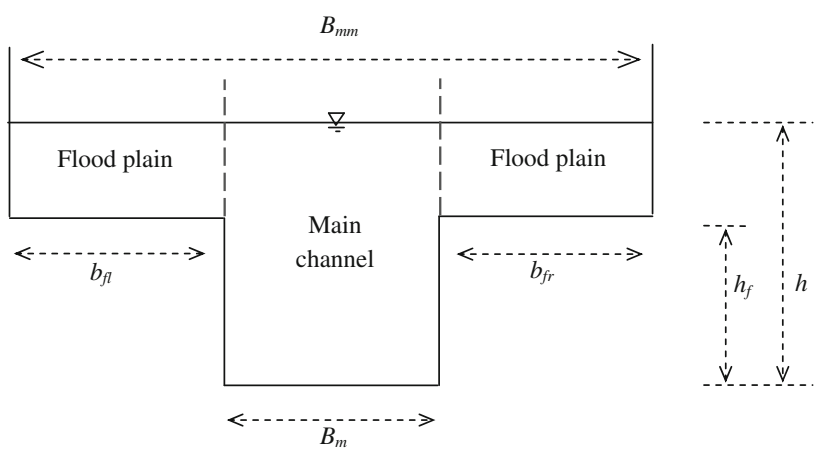

Figure 2. Illustrative sketch of rectangular compound channel. main channel velocity and is assumed to be uniform within each sub-section. This method assumes that there is no shear stress across the lines separating main channel and flood plains. It was demonstrated conclusively by Costabile and Macchione [45] that NIDC method for main channel - flood plain interaction on flood wave movement gives erroneous results and one should use the IDC method. Therefore, this method is adopted in the present model. IDC method considers the interaction between flood plain and main channel flows [41, 44, 46, 47, 49] and the equations for momentum correction factor, $\beta$ and slope of energy grade line, $S_{f}$ are modified accordingly. Among the several methods, the method proposed by Huthoff et al [47] is the simplest and is adopted here. Huthoff et al [47] have presented a method to calculate the total discharge through a compound channel section based on shear stress at the interface between main channel and flood plain. The final expression of total discharge is expressed in terms of average velocities in the subdivisions. First the average velocities in each sub-division are obtained using the Manning's equation, without considering the interaction. These velocities are then corrected for the interaction at the interface. Application of Huthoff et al [47] method to a compound channel flow leads to the following equations for $\beta$ and $S_{f}$.

$$
\begin{aligned}
& \beta=\frac{\left(c_{3} * A_{M}\right)+\left(c_{4} * A_{f r}\right)+\left(c_{5} * A_{f l}\right)}{\left(\sqrt{c_{3}} * A_{M}+\sqrt{c_{4}} * A_{f r}+\sqrt{c_{5}} * A_{f l}\right)^{2}} \\
& *\left(A_{M}+A_{f r}+A_{f l}\right) \\
& S_{f}=\frac{Q_{\text {total }}^{2}}{\left(\sqrt{M_{m}} * A_{M}+\sqrt{M_{f r}} * A_{f r}+\sqrt{M_{f l}} * A_{f l}\right)^{2}} \\
& M_{m}=\left(\frac{R_{m}^{4 / 3}}{n_{m}^{2}}\right) ; \quad M_{f l}=\left(\frac{R_{L}^{4 / 3}}{n_{f l}^{2}}\right) ; \quad M_{f r}=\left(\frac{R_{R}^{4 / 3}}{n_{f r}^{2}}\right) \\
& C_{1}=\frac{\frac{1}{2} * \gamma * \varepsilon_{M}}{1+\frac{1}{2} * \gamma\left(2 * \varepsilon_{M}+\varepsilon_{f r}\right)} \\
& C_{2}=\frac{\frac{1}{2} * \gamma * \varepsilon_{M}}{1+\frac{1}{2} * \gamma\left(2 * \varepsilon_{M}+\varepsilon_{f l}\right)} \\
& C_{3}=M_{m}-C_{1} *\left(M_{m}-M_{f r}\right)-C_{2} *\left(M_{m}-M_{f l}\right) \\
& C_{4}=M_{m f r}+C_{1} *\left(\frac{\varepsilon_{f r}}{\varepsilon_{M}}\right) *\left(M_{m}-M_{f r}\right) \\
& C_{5}=M_{m f l}+C_{2} *\left(\frac{\varepsilon_{f l}}{\varepsilon_{M}}\right) *\left(M_{m}-M_{f l}\right) \\
& \gamma=0.018 * \frac{B_{m m}}{B_{m}}
\end{aligned}
$$

where $A_{M}, A_{L}$ and $A_{R}$ are areas of main channel and flood plains on both sides. $c_{1 M}, c_{1 L}$ and $c_{1 R}$ are the corrected 
velocities with interaction in the individual sub-sections. $R_{M}, R_{L}$, and $R_{R}$ are hydraulic radius of main channel and flood plain. $n_{M}, n_{L}$, and $n_{R}$ are Manning's roughness coefficient of main channel and flood plains. $\varepsilon_{M}, \varepsilon_{L}$, and $\varepsilon_{R}$, are ratio of water depth at interface and friction factor multiplied by perimeter of each sub-section. $\gamma$ is an empirical constant whose suggested value is equal to 0.02 [47].

\subsection{Subsurface flow equations}

In the present study, sub-surface flow in the unsaturated medium is modeled as one-dimensional flow. Each section of the channel (node of the surface flow) is attached to a one dimensional subsurface column and the flow in this column is assumed to be one dimensional in the vertical direction (figure 1). It is assumed that Darcy's Law is applicable for evaluating the sub-surface flow velocity. It is also assumed that (i) compressibility of the medium and the water are negligible and (ii) the air phase is stagnant and is at atmospheric pressure. The governing Richards equation for one dimensional unsaturated flow in mixed form, without sources and sinks in the flow domain, is given as [50]

$$
\frac{\partial \theta}{\partial t}=\frac{\partial}{\partial z}\left[K(\psi)\left(\frac{\partial \psi}{\partial z}-1\right)\right],
$$

where $\theta=$ moisture content; $\psi=$ pressure head $(\mathrm{m})$; $K(\psi)=$ unsaturated hydraulic conductivity $(\mathrm{m} / \mathrm{s})$ which depends on the pressure head, $\psi$ and $z$ is the direction of flow in the subsurface part, taken as positive in the downward direction.

Functional relationships are needed to describe the relationship between the hydraulic conductivity, $K$, the moisture content, $\theta$ and the pressure head, $\psi$. In this study, hysteresis effect in the soil characteristics i.e., $\psi-K$ and $\psi-\theta$ relationships, is neglected. The soil water retention and relative permeability curves proposed by Van Genuchten [51] as given below are considered:

$$
\begin{gathered}
S_{e}(\psi)=\frac{\theta_{s}-\theta_{r}}{1-\theta_{r}}=\left\{\begin{array}{l}
\frac{1}{\left[1+(\alpha|\psi|)^{n}\right]^{m}} \ldots \text { for } \psi<0 \\
1 \ldots \text { for } \psi \geq 0
\end{array}\right\} \\
K\left(S_{e}\right)=S_{e}^{1 / 2}\left[1-\left(1-S_{e}^{1 / m}\right)^{m}\right]^{2}
\end{gathered}
$$

where $\theta_{s}$ and $\theta_{r}$ are saturated and residual moisture contents, $S_{e}$ is effective moisture content, $\alpha$ and $n$ are the Van Genuchten fitting parameters with $m=1-1 / n$.

\subsection{One-dimensional surface and pseudo two- dimensional sub-surface (1DS-P2DSS) model}

The mathematical model as presented earlier (figures 1, 3a) considers one-dimensional surface flow and one-

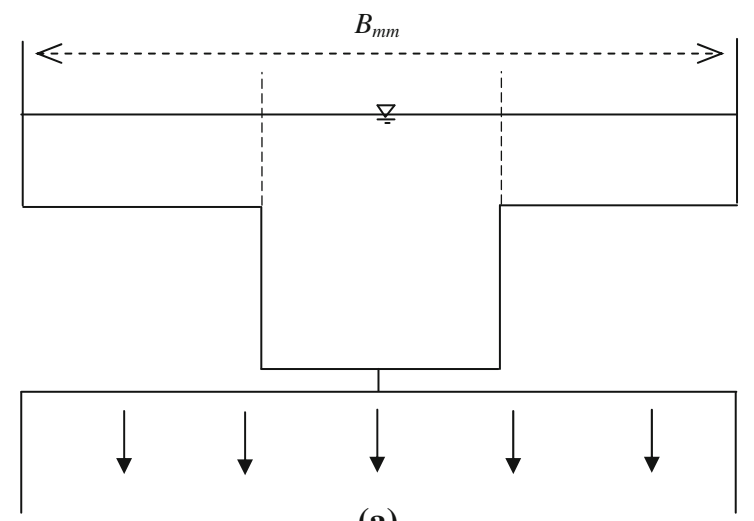

(a)

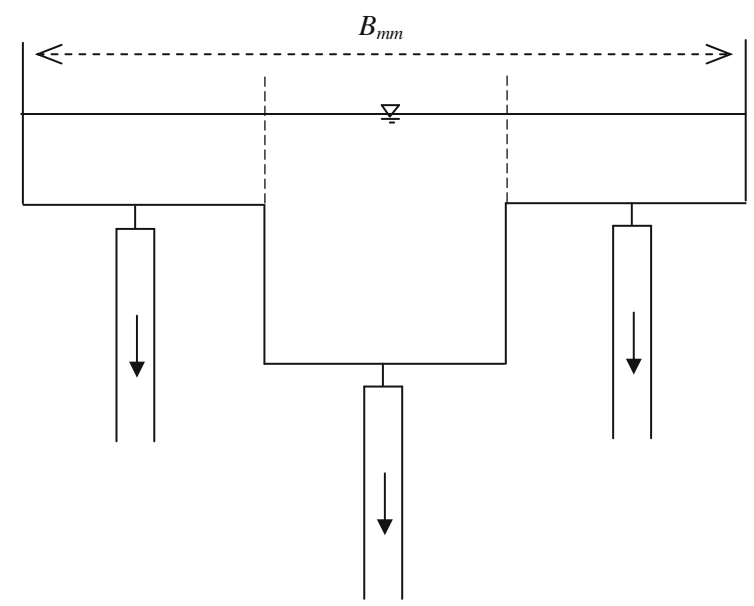

(b)

Figure 3. Schematic for (a) 1DS1DSS model; (b) 1DSP2DSS model.

dimensional sub-surface flow (1DS1DSS). In this model, the infiltration rate is assumed to be uniform across the cross section. This type of model has been applied earlier for ephemeral channels [15]. 1DS1DSS uses a constant infiltration rate across the channel width and multiplies it with channel top width to obtain the $Q_{l}$ value. Therefore, this model is not applicable for compound channels with large flood plains. In a compound channel, wetting of flood plains at any location occurs at a much later time than the wetting of corresponding main channel portion. The flow depth on the flood plain is smaller than the flow depth in the main channel. Also, the surface sealing characteristics in the flood plain may be different from the surface sealing characteristics in the main channel. These factors result in difference in infiltration rates from the flood plains and the main channel. In this study, a simple alternative model is proposed wherein the variation in infiltration rate across the cross-section is considered. The compound cross-section is linked to multiple soil columns across the cross section as shown in figure $3 \mathrm{~b}$. Movement of sub-surface water in each of these soil columns is assumed to occur vertically downwards (one-dimensional) and is determined 
separately. Also, the infiltration process from main channel portion and flood plain portions gets initiated only after that particular portion gets wetted by the arriving flood wave. This model is referred to as one-dimensional surface and pseudo two-dimensional sub-surface (1DSP2DSS) model in this study.

The 1DSP2DSS model is similar to 1DS1DSS model, but the variation in infiltration rate across the channel width is accounted for (figure $3 \mathrm{~b}$ ) analyzing the effect of perimeter dependent infiltration during flood flow movement in the flood plains of compound channels.

\section{Numerical solution}

\subsection{Surface flow}

The equations for the surface and subsurface flows are a set of non-linear partial differential equations and these equations are solved using numerical methods. The high resolution Lax-Friedrichs scheme is used to solve the partial differential equations for surface flow $[52,53]$. This is an explicit predictor-corrector Essentially Non-Oscillating (ENO) scheme. The main advantages of this scheme are its simplicity and the ability to resolve sharp gradients without any numerical oscillations. Equations (1) and (2) are written in vector form for convenience and all further explanations are done using this vector form. The equations can be written as

$$
\begin{gathered}
\frac{\partial W}{\partial t}+\frac{\partial F}{\partial x}=S \\
W=\left\{\begin{array}{c}
A \\
Q
\end{array}\right\} \\
F=\left\{\begin{array}{c}
Q \\
g F_{p}
\end{array}\right\} \\
S=\left\{\begin{array}{c}
-Q_{l} \\
g A\left(S_{0}-S_{f}\right)
\end{array}\right\} .
\end{gathered}
$$

3.1a Predictor part: The channel is divided into a number of finite-volume cells and the predicted value of $W$ for any cell $i, W_{i}^{p}$ is obtained as

$$
W_{i}^{p}=W_{i}^{t}-\frac{\Delta t}{\Delta x}\left[F_{i+1 / 2}^{t}-F_{i-1 / 2}^{t}\right]+\Delta t * S_{i}^{t},
$$

where $F_{i+1 / 2}^{t}$ represents the numerical flux through the face between the cells $i+1$ and $i, F_{i-1 / 2}^{t}$ represents the numerical flux through the face between the cells $i-1$ and $i, \Delta x$ is the cell spacing and $\Delta t$ is the computational time step. In this equation, subscript $i$ represents the value for cell $i$ and the superscript $t$ represents the value at time level $t$. The numerical flux $F_{i+1 / 2}^{t}$ is computed using the following formula.

$$
F_{i+1 / 2}=\frac{1}{2}\left[F_{R}+F_{L}-\alpha\left(W_{R}-W_{L}\right)\right],
$$

where $\alpha=$ a positive coefficient, $F_{R}$ and $F_{L}$ are fluxes computed at a cell using the information from the right and left sides of the cell face. They are computed using $W_{R}$ and $W_{L}$, respectively. $W_{L}$ and $W_{R}$ are obtained using the equations

$$
\begin{gathered}
W_{L}=W_{i}+\frac{\delta W_{i}}{2} \\
W_{R}=W_{i+1}-\frac{\delta W_{i+1}}{2}
\end{gathered}
$$

$\delta W_{i}$ and $\delta W_{i+1}$ are determined using the minmod limiter function $[53,54]$.

$$
\begin{array}{r}
\delta W_{i}=\min \bmod \left(W_{i+1}-W_{i}, W_{i}-W_{i-1}\right) \\
\delta W_{i+1}=\min \bmod \left(W_{i+1}-W_{i}, W_{i+2}-W_{i+1}\right)
\end{array}
$$

The positive coefficient $\alpha$ is determined using the maximum value (for all the grid points) of the largest Eigen value, $\lambda$ of the Jacobian of the system of equations.

$$
\alpha \geq \max \left(\lambda_{i}\right)
$$

The predicted values of $A$ and $Q$ at unknown time level are obtained from vector Eq. (20). Value of flow depth, $h$ is determined from $A$ using the geometric characteristics of the cross section.

3.1b Corrector part: Values of $Q$ and $A$ at the time level $t+\Delta t$ are obtained using the following vector equation, and the predicted values and the values at the time level $t$.

$$
W_{i}^{t+\Delta t}=\left[W_{i}^{t}-\frac{\Delta t}{\Delta x}\left[F_{i+1 / 2}^{p}-F_{i-1 / 2}^{p}\right]+\Delta t * S_{i}^{p}\right],
$$

where

$$
F_{i+1 / 2}^{p}=\frac{1}{2}\left[F_{R}^{p}+F_{L}^{p}-\alpha\left(W_{R}^{p}-W_{L}^{p}\right)\right]
$$

$W_{R}^{p}$ and $W_{L}^{p}$ are determined from $W_{i+1}^{p}$ and $W_{i}^{p}$ using the same $\delta W_{i+1}$ and $\delta W_{i}$ as determined in the predictor step. This procedure results in better numerical stability.

3.1c Initial and boundary conditions: Although the initial flow depth and discharge are equal to zero, a very thin film of depth $h_{i n i}$ and corresponding flow area, $A_{i n i}$ discharge, $Q_{\text {ini }}$ are assumed to exist at time $t=0$. This assumption is made to overcome the numerical singularity in a simple way. Value of $h_{i n i}$ was chosen as small as possible, and in the present study it is equal to $5 \mathrm{~mm}$. Numerical experiments showed that the simulated results were not sensitive to the $h_{i n i}$ value as long as it is small.

The inflow discharge hydrograph is specified as the boundary condition at the upstream end. The procedure 
outlined by Garcia-Navarro et al [55] is adopted for determining the flow area, $A$ and the corresponding flow depth $h$ at the upstream end. This procedure is adopted because flash floods, like dam break flows, could result in supercritical flow conditions at the upstream end. The flow depth at the upstream end is determined using the negative characteristic equation in case the flow is subcritical there [56]. A simple extrapolation procedure is adopted to determine $A$ and $Q$ at the downstream end.

The chosen scheme is an explicit scheme and therefore, to ensure stability, the time step, $\Delta t$ is determined using the Courant-Friedrichs-Lewy (CFL) stability condition. $\Delta t$ is chosen dynamically in the model.

\subsection{Subsurface flow}

To determine the infiltration rate $Q_{l}$ in the continuity equation, the one-dimensional Richard equation (Eq. 13) for $z$ direction has to be solved. The surface flow depth at that point is considered as the top boundary condition (at $z=0$ ) while solving the Richards equation. A semi-implicit finite volume model [57] is adopted for solving the Richards equation in mixed form so that mass balance is ensured regardless of time step and cell sizes. Referring to finite volume cell arrangement shown in figure 1 , the moisture content, $\theta$ and the pressure head, $\psi$ are specified at the center of the cell, while the velocities are specified at the cell faces. The subscript $j$ refers to the cell number in the $z$-direction. The superscripts $t$ and $t+\Delta t$ refer to the known and unknown time levels, respectively. Equation (13) is discretized as follows:

$$
\frac{\theta_{j}^{t+\Delta t}-\theta_{j}^{t}}{\Delta t}+\frac{\overline{V_{d}}-\overline{V_{u}}}{\Delta z}=0,
$$

where $V_{u}$ is the velocity at the upstream (top) cell face, $V_{d}$ is the velocity at the downstream (bottom) cell face and the bar is used to denote the time averaged value. $\Delta z$ is the cell spacing in the $z$ direction. The time averaged velocities are determined by

$$
\bar{V}=0.5 *\left(V^{t+\Delta t}+V^{t}\right) .
$$

The velocity at the cell face is determined using the Darcy's equation and pressure heads at the neighboring cell centers. For example, $V_{d}$ is obtained from pressure heads $\psi_{j+1}$ and $\psi_{j}$ using the following equation:

$$
V_{d}=-K_{d}\left[\left(\psi_{j+1}-\psi_{j}\right)-\Delta z\right] / \Delta z,
$$

where $K_{d}$ is the unsaturated hydraulic conductivity evaluated at the face between cells $j$ and $j+1$. It is equal to the average value of $K$ at the neighboring cell centers, evaluated using the $\psi$ values at the cell centers and Eqs. (14) and (15). Substitution of Eqs. (30) and (31) in Eq. (29) leads to the following general discretized equation for any cell $j$,

$$
\begin{aligned}
& \frac{0.5 * \Delta t}{\Delta z^{2}}\left[-K_{d}^{t+\Delta t}\left(\psi_{j+1}^{t+\Delta t}-\psi_{j}^{t+\Delta t}-\Delta z\right)\right. \\
& \left.\quad+K_{u}^{t+\Delta t}\left(\psi_{j}^{t+\Delta t}-\psi_{j-1}^{t+\Delta t}-\Delta z\right)\right] \cdots \\
& \cdots+\theta_{j}^{t+\Delta t}-\left[\theta_{j}^{t}-(0.5) \frac{\Delta t}{\Delta z}\left(V_{d}^{t}-V_{u}^{t}\right)\right]=0
\end{aligned}
$$

Equation (32) is written for all the cells in the sub-surface flow domain to obtain a set of simultaneous non-linear algebraic equations in the unknowns $\psi_{j}^{t+\Delta t} . K_{d}^{t+\Delta t}, K_{u}^{t+\Delta t}$ and $\theta_{j}^{t+\Delta t}$ are obtained from $\psi_{j-1}^{t+\Delta t}, \psi_{j}^{t+\Delta t}$ and $\psi_{j+1}^{t+\Delta t}$ using Eqs. (14) and (15). This set of non-linear equations is solved using Newton-Raphson iteration technique to obtain $\psi_{j}^{t+\Delta t}$ at all cells $j$.

3.2a Boundary conditions: In the adopted scheme, cells are arranged in such a way that the upstream most cell face coincides with the ground surface. Surface flow depth at this location is specified as the boundary condition. Let $\psi_{b}$ be the imposed boundary pressure head at the ground surface. This imposed pressure head $\psi_{b}$ is used along with the values of $\psi_{1}$ and $\psi_{2}$ to determine the flux at the ground surface as given below.

$$
V_{z}(\text { at } \mathrm{z}=0)=-K\left(\psi_{b}\right)\left[\left(\frac{-8 * \psi_{b}}{3}+3 \psi_{1}-\frac{\psi_{2}}{3}\right) / \Delta z-1\right] .
$$

It should be noted here that the flux at the ground surface is taken as zero for all times prior to arrival of the flood wave at that location. A simple extrapolation boundary condition is applied at the bottom boundary since this boundary is taken fairly deep and the moisture front would not reach this location within the stipulated computational time.

\subsection{Surface and subsurface flow coupling}

Flow depth obtained from the solution of surface flow is used for specifying the top boundary condition while solving the Richards equation. On the other hand, infiltration rate (flux at the top face) obtained from the solution of sub-surface is used to determine the $Q_{l}$ value in the surface flow equations. There are many alternative ways in which the surface and subsurface components can be coupled [58]. In this study, a semi-coupled method as suggested by Mudd [15] is adopted for coupling the surface and subsurface flow components.

1. The surface flow equations are solved neglecting all the source terms to determine the discharge and the flow depth at the predicted time level (Eq. 20);

2. Average values of the flow depth and discharge are determined using Eqs. (34) and (35) as follows 


$$
\begin{gathered}
h_{\text {avg }}(i)=\frac{\left(h^{p}+h^{t}\right)}{2} ; \\
Q_{a v g}(i)=\frac{\left(Q^{p}+Q^{t}\right)}{2} ;
\end{gathered}
$$

where $h^{p}$ and $Q^{p}$ are the flow depth and discharge at the predicted time level. $h^{t}$ and $Q^{t}$ are the flow depth and discharge at the time level $t$;

3. The value of flow depth from step 2 at any location $i$ is used as top boundary condition while solving the subsurface flow equation and corresponding infiltration rate is obtained as part of the solution;

4. The average values of flow depth and flow rate are used for determining the friction term in the momentum equation for surface flow;

5. The infiltration rate from step 3 and the friction terms from step 4 are now used in the surface flow equations, to determine the flow depth and the discharge at the next time level.

6. Step 1-5 are repeated till the required time level.

\section{Results and discussion}

\subsection{Verification of the model}

Comprehensive experimental data, either laboratory or field, is not available for flood routing in ephemeral channels with compound cross-sections. Therefore, the model presented in the previous sections is verified in three stages. First, the surface flow component for routing in compound channels is verified by comparing the results obtained using the present model with the laboratory experimental data of Lai et al [59]. The surface flow component is also verified using results obtained by Cao et al [41] and Costabile and Macchione [45] for a trapezoidal compound channel. Next the solution for Richards equation is verified by comparing the results obtained using the present model with those presented by Mudd [15] for a sediment column subjected to a constant ponding depth. Finally, the coupled surface and sub-surface flow model is verified by comparing the results obtained using the present model with those available in Mudd [15] for the case of a flood in a rectangular channel. Verification of the proposed model for the above cases is discussed in the following sections.

4.1a Case 1: Verification of surface flow component with experimental data: The surface flow component of the present model is verified with laboratory experimental data obtained by Lai et al [59] for a compound channel. The dimensions of laboratory channel used by Lai et al [59] are as follows: channel longitudinal slope $=0.001$, side slopes of channels banks for both main channel and flood plain $=1.0$; main channel width $=0.1 \mathrm{~m}$ and depth below the flood plain $=0.05 \mathrm{~m}$. Manning's $\mathrm{n}$ for main channel and flood plains are 0.012 and 0.013 , respectively. Length of the channel is $5.1 \mathrm{~m}$. Measured inflow hydrographs for two cases identified by Lai et al [59] as MDFj25b (Medium Duration Flood) and SDFj25c (Short duration flood) are used for specifying the upstream boundary condition in the numerical runs. IDC method was used for modeling the flood plain and main channel flow interaction. Measured flow depths at a station $3.4 \mathrm{~m}$ from the inlet are used for comparing the simulated and experimental data. In the numerical runs, a spatial step, $\Delta x=0.1 \mathrm{~m}$ is used. Figure $4 \mathrm{a}$, b compares the numerically simulated flow depth variation with the measured data of Lai et al [59] for MDF and SDF runs, respectively. It can be observed from figure $4 a, b$ that the numerical model is able to simulate the flow conditions in compound channel satisfactorily, except for slight lag of rising limb (approximately $15 \mathrm{~s}$ ) in case of MDF and slight under prediction of peak value (approximately $5 \mathrm{~mm}$ ) in case of SDF.

4.1b Case 2: One-dimensional surface flow in a trapezoidal compound channel: In this section, the surface flow component is verified by comparing the results obtained using the present model with the numerical results available in literature for bench mark problems [41, 45].

Case 2A: A trapezoidal prismatic compound open channel, as shown in figure 5 , is considered for the purpose of illustration. This illustrative channel is the same as that considered by Cao et al [41] in their study. The specified geometrical parameters are as follows: length of the channel $=150 \mathrm{~km}$, channel bottom width, $B_{m}=20 \mathrm{~m}$, bed slope, $S_{o}=0.0002$, main channel side slopes $\left(s_{m l}\right.$ and $\left.s_{m r}\right)=3$; flood plain side slopes $\left(s_{f l}\right.$ and $\left.s_{f r}\right)=3.0$; main channel depth, $h_{f}=5 \mathrm{~m}$ and flood plain widths $\left(b_{f}\right.$ and $\left.b_{f r}\right)=175 \mathrm{~m}$. The Manning's roughness coefficient, $n$ for both the main channel and flood plain is taken as 0.03 .

Initially, the flow in the channel is assumed to be in steady state conditions with a uniform discharge, $Q_{i n i}=120 \mathrm{~m}^{3} / \mathrm{s}$, and water depth, $h_{i n i}=3.98 \mathrm{~m}$, throughout the channel length along the flow direction. A hydrograph having a Log-Pearson Type-III distribution with four parameters is imposed at the upstream boundary. This is the same hydrograph considered by Cao et al [41] in their study. The expression for this hydrograph is

$$
Q(t)=Q_{b}+\left(Q_{p}-Q_{b}\right) *\left[e^{\frac{-\left(t-t_{p}\right)}{\left(t_{c}-t_{p}\right)}}\right] *\left[\left(\frac{t}{t_{p}}\right)^{\frac{t_{c}}{\left(t_{c}-t_{p}\right)}}\right]
$$

In which, $t=$ current time, $Q_{b}$ (base flow or initial uniform flow $)=120 \mathrm{~m}^{3} / \mathrm{sec}, Q_{\text {peak }}($ peak flow $)=1,200 \mathrm{~m}^{3} / \mathrm{sec}, t_{p}$ (time to peak) $=15 \mathrm{~h}$, and $t_{c}$ (time to centroid of the input hydrograph) $=18 \mathrm{~h}$. For this initial and boundary conditions, the flow is completely in main channel at $t=0$. Further, as the flood wave arrives the water level starts rising and then flows over the flood plain. Simulated discharge hydrograph at $100 \mathrm{~km}$ downstream obtained using 


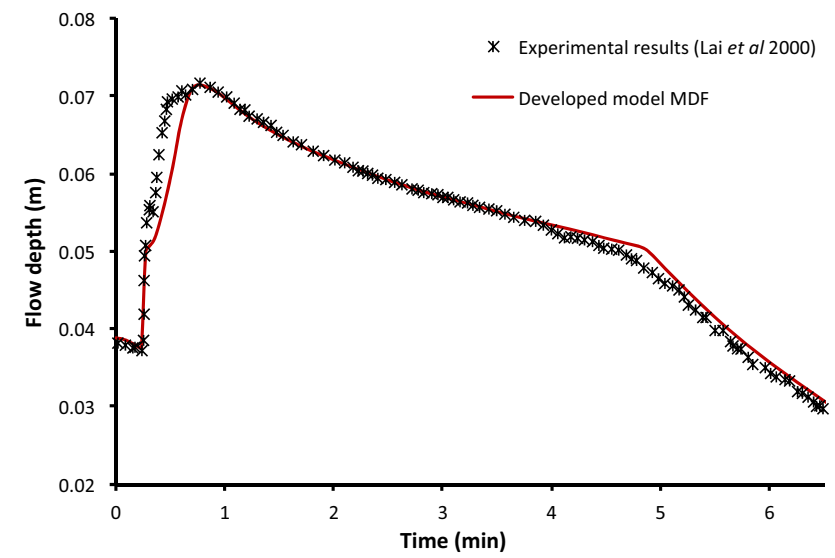

(a)

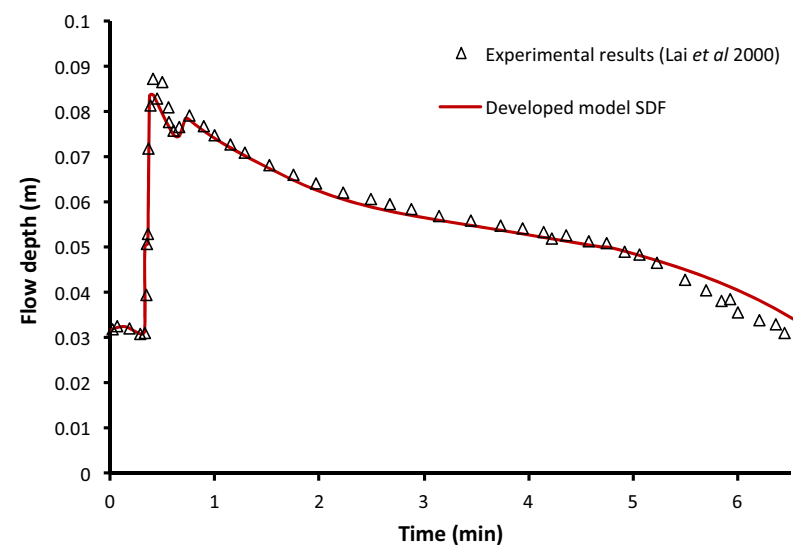

(b)

Figure 4. Validation of developed model with Lai et al [59] Case 1, (a) MDF - j25b; (b) SDF - j25c.

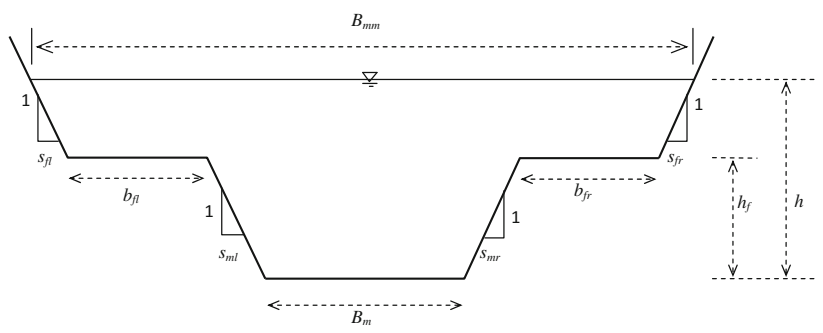

Figure 5. Compound channel cross-section for Case 1.

the present model is compared with the results obtained by Cao et al [41] in figure 6. It can be seen from this figure that the present model results match very well with those obtained earlier by Cao et al [41].

Case 2B: The model for surface flow in a compound channel is also verified using the data presented in Costabile and Macchione [45]. A triangular hydrograph as given in Eq. (37) is imposed at the upstream boundary.

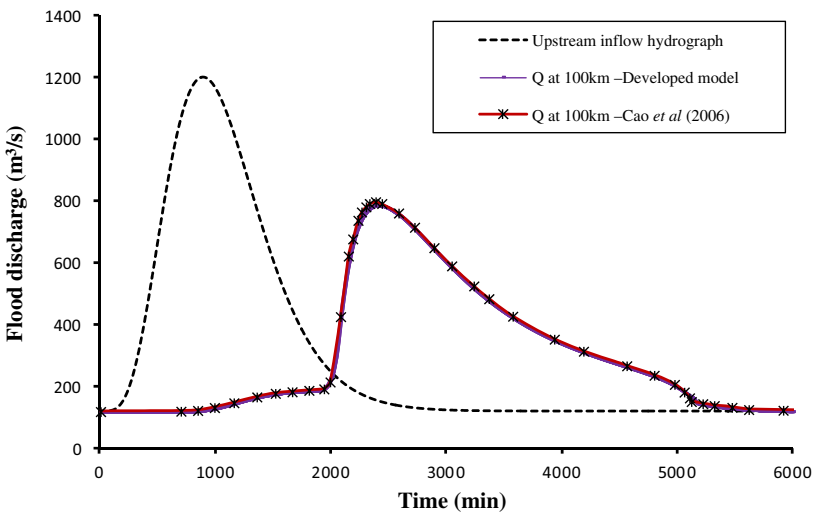

Figure 6. 1-D surface flow model for Case 2A - Discharge hydrograph.

$$
Q(t)=Q_{b}+\left(Q_{p}-Q_{b}\right)\left[\frac{t}{t_{p}} e^{\left(1-\frac{t}{t_{p}}\right)}\right]^{c} .
$$

The specified parameters are as follows: $Q_{b}$ (base flow or initial uniform flow) $=7 \mathrm{~m}^{3} / \mathrm{s}, Q_{\text {peak }}$ (peak flow) $=222 \mathrm{~m}^{3} /$ $\mathrm{s}, t_{p}$ (time to peak) $=3 \mathrm{~h}, c=3.2$ and initial uniform water depth, $h_{i n i}=1.5 \mathrm{~m}$. Specified channel parameters are main channel width $=15 \mathrm{~m}$; total width of the channel $=100$ $\mathrm{m}$; depth to the flood plain $=1.5 \mathrm{~m}$, main channel and flood plain channel roughness coefficients $\left(n_{m c}\right.$ and $\left.n_{f p}\right)=0.02$ and 0.04 and channel longitudinal slope $=0.05 \%$. Simulated discharge hydrograph and flow depth at $10 \mathrm{~km}$ downstream obtained using the present model are compared with the results obtained by Costabile and Macchione [45] in figure 7a, b. These simulations are carried out using the IDC method for flood routing. Once again it can be observed that the results obtained using proposed model match closely with the results obtained earlier by Costabile and Macchione [45]. There was only a marginal difference (less than 5\%) in the simulation of peak discharge value. Results presented in this section demonstrate that the proposed model simulates the flood wave movement in channels with compound cross-sections satisfactorily.

It may be noted here that the purpose of discussion presented in this and the previous sub-section is to demonstrate that the proposed model gives results comparable to the existing models, for the case of surface flow in compound channels, in the absence of infiltration loss. While the existing models for compound channels cannot simulate flows with infiltration loss, the present model can simulate flood flows which are significantly affected by infiltration losses. The capability of present model for simulating infiltration process is demonstrated in the following sections.

4.1c Case 3: Infiltration rate for a soil column subjected to constant ponding depth: This study has been carried out to verify the numerical solution for Richards equation by 


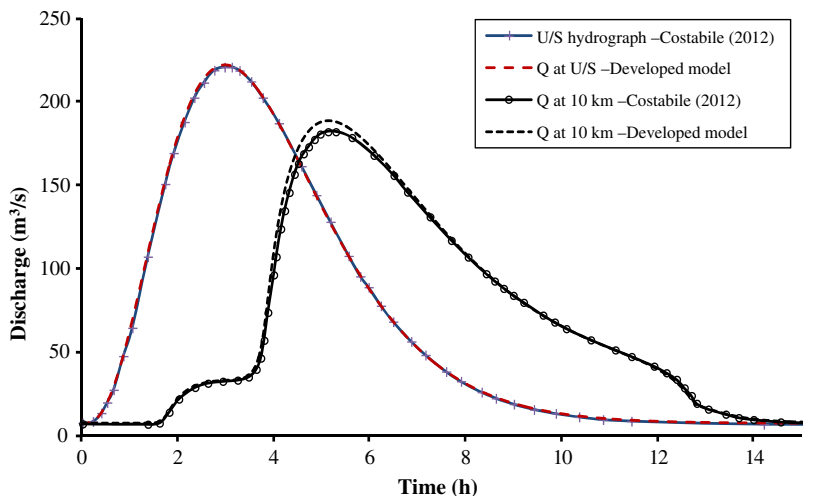

(a)

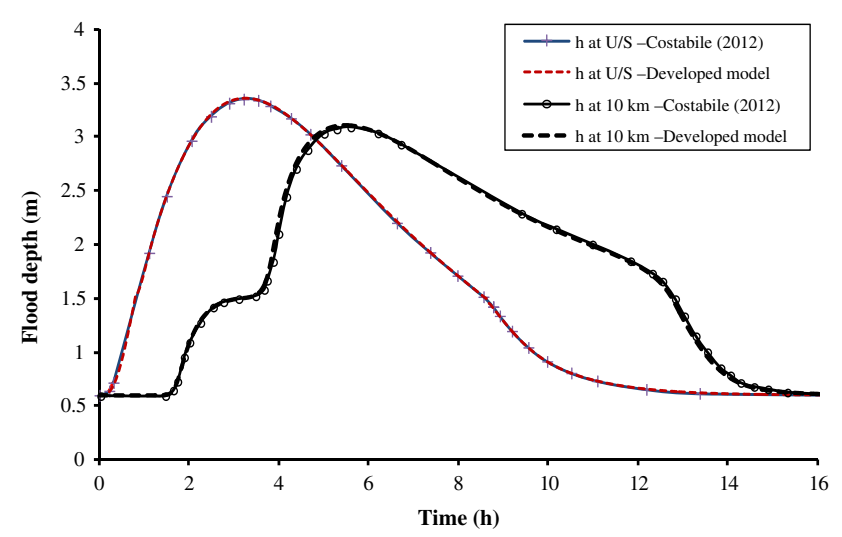

(b)

Figure 7. 1-D surface flow model results for Case 2B: (a) Discharge hydrograph; (b) Depth hydrograph.

comparing the results obtained using the present model with those presented by Mudd [15] for a sediment column subjected to a constant ponding depth of water $2 \mathrm{~m}$ above the surface at a particular node in the channel. The subsurface model inputs are residual moisture content $\left(\theta_{\text {res }}\right)=0.102$, saturated moisture content $\left(\theta_{\text {sat }}\right)=0.368$, saturated hydraulic conductivity $\left(K_{\text {sat }}\right)=0.00922 \mathrm{~m} / \mathrm{s}$ and the van Genchten parameter, $\alpha=0.0335 \mathrm{~m}$. It can be observed from figure 8 that the results obtained using the present model compare very well with those presented by Mudd [15]. Peak value and the steady state infiltration values are matching closely. There is a small difference of $0.01 \mathrm{~mm} / \mathrm{s}$, for $500 \mathrm{~s}$ during transition period.

4.1d Case 4: 1DS1DSS model for rectangular channel: 1DS1DSS flood routing model is developed by solving complete 1-D shallow water flow equations, and mixed form of 1D Richards equation for unsaturated subsurface flow. The interaction between surface flow component and subsurface flow component is incorporated through an iterative coupling procedure as explained in section 3.3. The developed model was verified by comparing results obtained using the present model with those obtained by Mudd [15] for the case of flood routing in a rectangular channel. The model inputs are channel bed

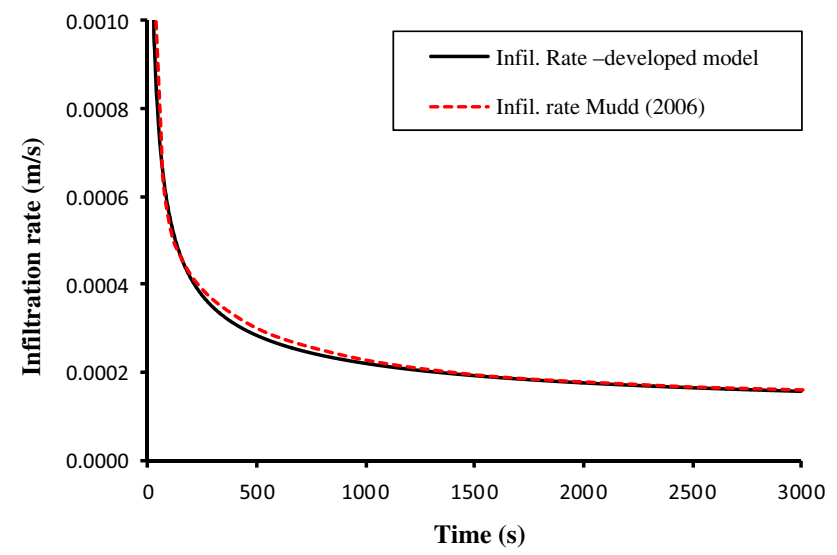

Figure 8. Comparison of infiltration rates in a sediment column: surface depth $=2 \mathrm{~m}$.

slope $=0.01$, Manning's roughness coefficient $=0.03$, length of channel $=8 \mathrm{~km}$, and width of channel $=2 \mathrm{~m}$. The inflow triangular hydrograph characteristics are maximum discharge $\left(Q_{\text {peak }}\right)=4 \mathrm{~m}^{3} / \mathrm{s}$, time to peak $\left(t_{\text {peak }}\right)=120 \mathrm{~s}$ and time to recession $\left(t_{\text {res }}\right)=5400 \mathrm{~s}$. The soil characteristics are the same as given in section $4.1 \mathrm{c}$. It is assumed that the channel had a thin layer of flow of $5 \mathrm{~mm}$ depth initially, to avoid singularity problem. Numerical experimentation showed that the results are not sensitive to this assumption as long as the initial assumed depth is below $5 \mathrm{~mm}$. Figure 9a, b shows the spatial variation of flow depth at $45 \mathrm{~min}$ of simulation time and temporal variation of flow discharge at $2 \mathrm{~km}$ downstream, obtained using the present model and by Mudd [15]. It can be observed that the simulation of flow rate variation by the proposed model is very good. Overall, simulation for water surface profile is also satisfactory, although differences occur at the wave front. This difference could be due to (i) the way surface and sub-surface flows are coupled and (ii) the differences in the numerical schemes adopted for solving the governing equations.

\subsection{Comparison of 1DS1DSS and 1DSP2DSS models}

It may be noted here that the purpose of discussion presented in the previous sub-section is to demonstrate that the proposed model gives results comparable to the existing models, for the case of flood routing in an ephemeral channel having a rectangular cross section. The existing one-dimensional models for flood routing in ephemeral channels cannot be applied for compound channels because they do not consider the lateral variation in infiltration across a cross-section. This lateral variation in infiltration rate arises due to different times of arrival of wave front in the main channel portion and flood plains, and the flow depth. It can also arise due to differences in soil characteristics of main channel and those of flood plains. The 


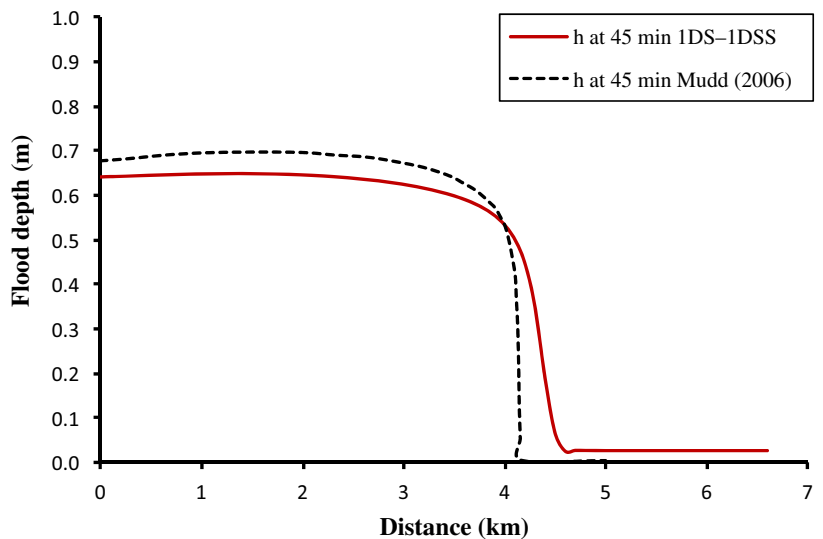

(a)

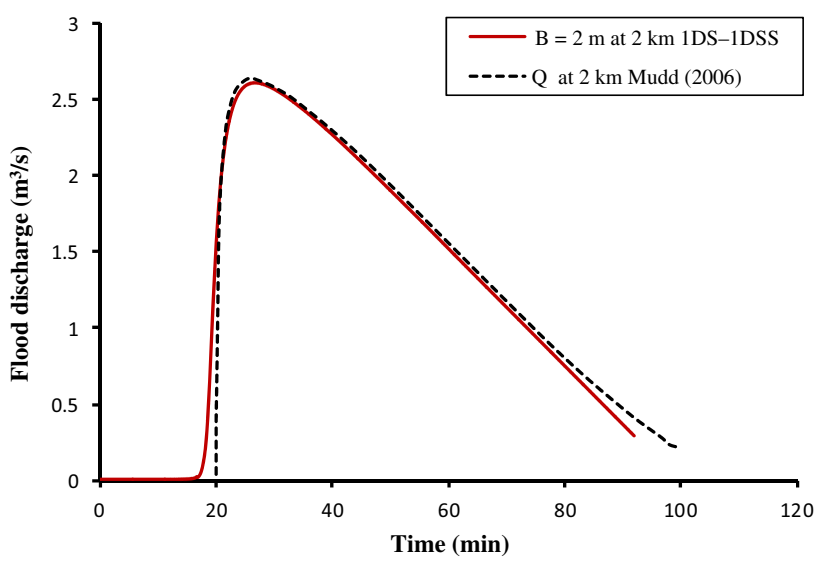

(b)

Figure 9. Flood routing in rectangular channel with infiltration for Case 4: (a) Water surface profile; (b) Discharge hydrograph at $2 \mathrm{~km}$.

model proposed in the present study (1DSP2DSS) takes this into account. In this section, we evaluate the errors that may result in flow computations if one ignores the lateral variation in infiltration rate while performing the flood routing in ephemeral channels. For this purpose, results obtained using the 1DSP2DSS model are compared with the results obtained using the 1DS1DSS model, for the same geometric and soil parameters. Comparison is made for two cases of flood plain width: $10 \mathrm{~m}$ and $50 \mathrm{~m}$. Input data for these simulations are as follows: main channel width $=5 \mathrm{~m}$; flood plain width $=10 \mathrm{~m} / 50 \mathrm{~m}$; depth to the flood plain $=1.0 \mathrm{~m}$ and slope of the channel $=0.05 \%$. The triangular inflow hydrograph is specified as upstream boundary condition with maximum discharge, $Q_{\text {peak }}=200 \mathrm{~m}^{3} / \mathrm{s}$, time to peak $t_{\text {peak }}=2 \mathrm{~min}$. The soil characteristics are the same as given in section 4.1c.

Case 5: Main channel and flood plains of equal roughness In this particular simulation, roughness coefficient for main channel $=$ roughness coefficient for flood plains $=0.02$. Results obtained for discharge and depth hydrographs at $x=3.0 \mathrm{~km}$ are presented in figure $10 \mathrm{a}, \mathrm{b}$. It

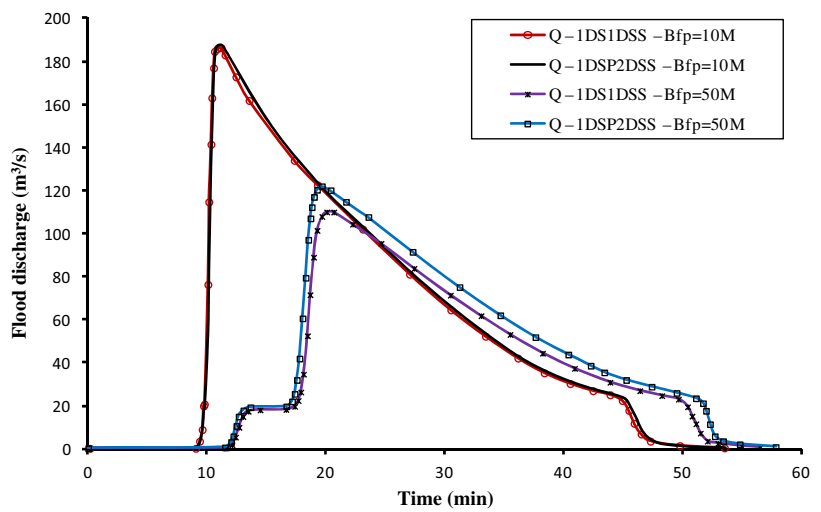

(a)

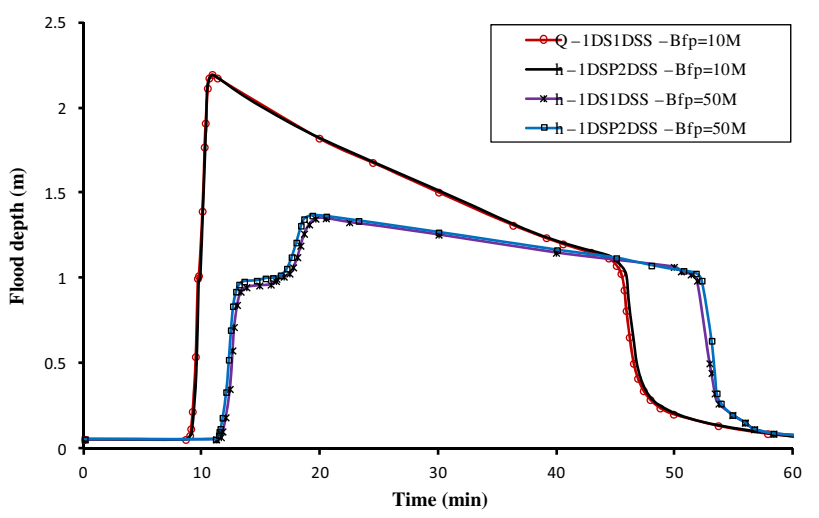

(b)

Figure 10. Comparison of 1DS1DSS and 1DSP2DSS models for Case 5: (a) Discharge hydrograph; (b) Depth hydrograph.

can be observed from figure 10a that ignoring the lateral variation in infiltration has not affected the movement of flood wave significantly in case of channels with narrow flood plains $\left(b_{f l}=b_{f r}=10 \mathrm{~m}\right)$. However, the effect is significant, with a difference of $12 \mathrm{~m}^{3} / \mathrm{s}(10 \%)$ in peak discharge, in the case of large flood plain widths $\left(b_{f}=-\right.$ $b_{f r}=50 \mathrm{~m}$ ). As can be expected, this effect gets magnified as the flood plain width increases. For example, in a case where the flood plain width is $150 \mathrm{~m}$ (results not shown here), the difference in peak discharge is equal to $59.3 \mathrm{~m}^{3} / \mathrm{s}$ (76\% from 1DS1DSS case). Consequently, there is a significant difference in the total amount of water infiltrated into the subsurface, if the lateral variation in infiltration rate is not considered. For the case of $50 \mathrm{~m}$ flood plain width, 1DS1DSS model results in a transmission loss of $75,060 \mathrm{~m}^{3}$ of water in the first $3.0 \mathrm{~km}$ length of channel, as compared to a value of $58,260 \mathrm{~m}^{3}$ given by the 1DP2DSS model. Thus the 1DS1DSS model over predicted the transmission loss by $22 \%$. It may be noted here that the surface flow depth causing the infiltration is less on the flood plains as compared to that in the main channel. Therefore, 1DS1DSS model which determines the loss based on single flow depth value corresponding to the main channel depth, over predicts the average infiltration rate as compared to 


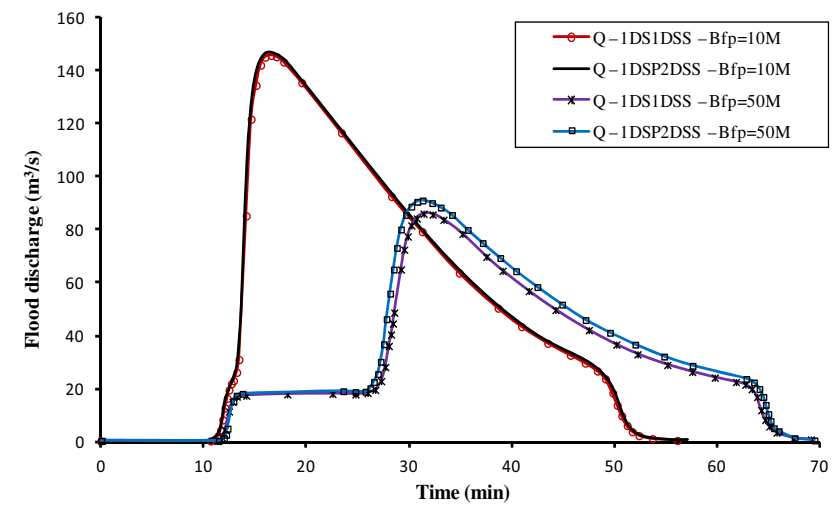

(a)

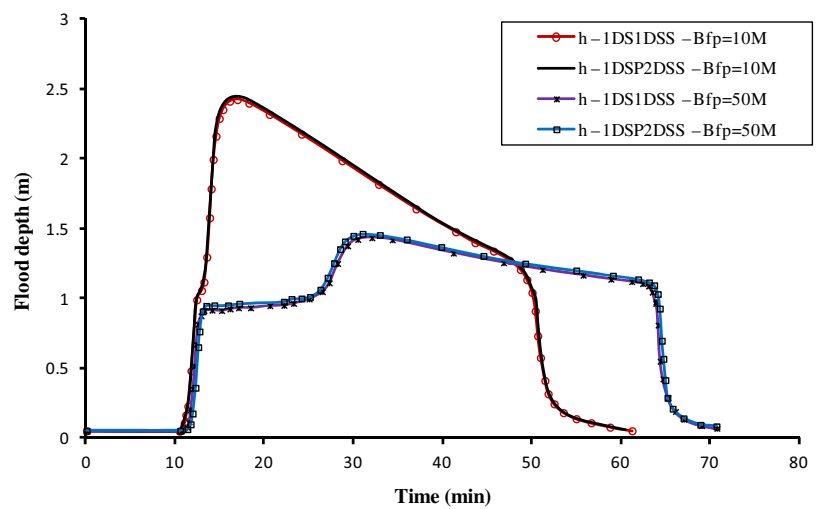

(b)

Figure 11. Comparison of 1DS1DSS and 1DSP2DSS models for Case 6 with rougher flood plains: (a) Discharge hydrograph; (b) Depth hydrograph.

1DSP2DSS model. Interestingly, ignoring the lateral variation in infiltration has not affected the depth hydrograph significantly for the simulations made here (figure 10b).

Case 6: Flood plains rougher than main channel In many natural cases, flood plains are much rougher than the main channel, and this difference in roughness has an effect on momentum transfer between the flood plain flow and the main channel flow. Therefore, simulations are carried out to estimate the difference between results obtained using 1DS1DSS and 1DSP2DSS models, when flood plains are rougher than main channel. Input data for these simulations are same as for case 5, except the Manning roughness coefficient for flood plains is taken as 0.04. Results obtained for discharge and depth hydrographs at $x=3.0 \mathrm{~km}$ are presented in figure $11 \mathrm{a}, \mathrm{b}$, respectively. It can be observed from figure 11 a that the $Q_{\text {peak }}$ lags and decreases by $30 \mathrm{~m}^{3} / \mathrm{s}$ when compared to $Q_{\text {peak }}$ value obtained when the flood plains are smoother (figure 10a) and flood plain width $=50 \mathrm{~m}$. Rougher flood plains induce more resistance and slow down the flood wave movement. The reduction in $Q_{\text {peak }}$ value is also due to an increased infiltration loss on the rougher flood plains. Interestingly, the difference between the results obtained using the
1DS1DSS and the 1DSP2DSS models is not as much as when the flood plains are smoother. The difference in transmission loss obtained using 1DS1DSS and 1DSP2DSS models is only $13.7 \%$, as compared to $22 \%$ for the earlier case. The difference in surface flow depths obtained using 1DS1DSS and 1DSP2DSS models is smaller in the case of channel with rougher flood plains, as compared to the case of channel with smoother flood plains. For example, difference in peak depths obtained using 1DS1DSS and 1DSP2DSS models is only $1 \mathrm{~cm}$ for the case of channel with rougher flood plains, while it is as much as $3.9 \mathrm{~cm}$ in the case of channel with smooth flood plains. Also, the difference in time base of hydrograph at any section obtained using 1DS1DSS and 1DSP2DSS models is smaller in the case of channel with rougher flood plains, as compared to the case of channel with smoother flood plains.

Case 7: Clogging layer in the main channel Many times, there could be a clogging layer in the channel, which reduces the infiltration loss. In the simulations presented in this section, it is assumed that the top soil layers in the main channel have a $K_{\text {sat }}$ value equal to $20 \mathrm{~cm} / \mathrm{h}$, as compared to a value of $33.2 \mathrm{~cm} / \mathrm{h}$ for flood plains. Rest of the soil layers below both main channel and flood plain have a $K_{\text {sat }}$ value $=33.2 \mathrm{~cm} / \mathrm{h}$. The schematic diagrams in figure $12 \mathrm{a}$, b illustrate the compound rectangular channel and infiltration component with clogging layer on both the main channel and flood plains. These simulations are performed to demonstrate why the proposed 1DSP2DSS model should be used instead of the usual 1DS1DSS model, when lateral variation in infiltration rate in a channel occurs not only because of difference in surface flow depth but also because of differences in soil properties. It is obvious that 1DS1DSS model is strictly not valid in such a case because it uses the same infiltration rate across the entire cross section (figure $12 \mathrm{a}$ ), based on the flow depth in the main channel and average soil characteristics.

Results obtained for discharge and depth hydrographs at $x=3.0 \mathrm{~km}$ are presented in figure $13 \mathrm{a}, \mathrm{b}$, respectively. The difference in $Q_{\text {peak }}$ values at $x=3.0 \mathrm{~km}$ simulated by 1DS1DSS and 1DSP2DSS models is $9.5 \mathrm{~m}^{3} / \mathrm{s}(9.9 \%)$. It should also be noted that, unlike in previous cases, the $Q_{\text {peak }}$ value simulated by 1 DS1DSS model is larger than that simulated by 1DSP2DSS model, indicating that 1DS1DSS model under predicts the transmission losses. This is expected because 1DS1DSS model takes $K_{\text {sat }}$ value of top layers equal to $20 \mathrm{~cm} / \mathrm{h}$ for entire width of the channel, whereas the correct value for flood plains $(33.2 \mathrm{~cm} / \mathrm{h})$ is larger than this. Transmission loss in $3.0 \mathrm{~km}$ stretch as simulated by the 1DS1DSS model is equal to $51,840 \mathrm{~m}^{3}$ while it is equal to $62,760 \mathrm{~m}^{3}$ (difference $=21 \%$ ) as simulated by the 1DSP2DSS model. These simulations demonstrate the usefulness of the 1DSP2DSS model for flood routing in compound channels where there is a lateral variation in infiltration rate at a cross section. 


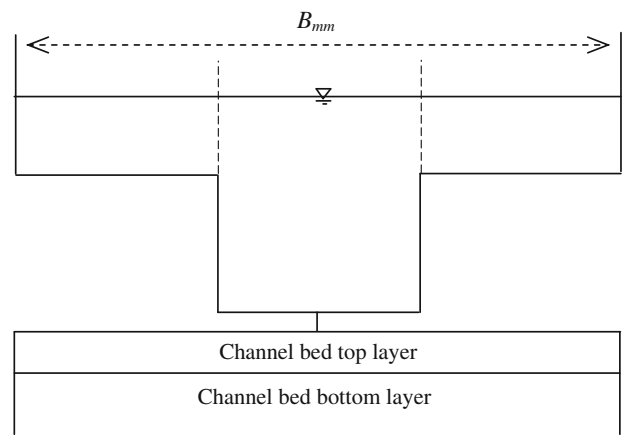

(a)

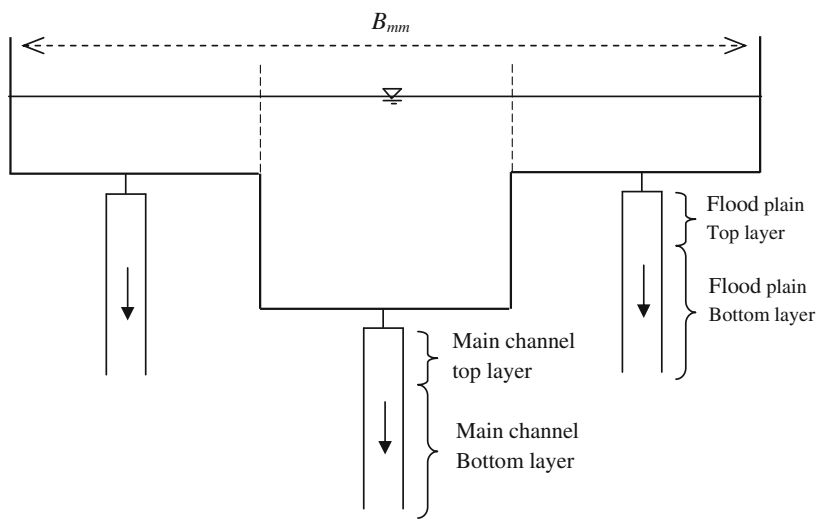

(b)

Figure 12. Schematic for model simulations with clogging layer: (a) 1DS1DSS; (b) 1DSP2DSSS.

\subsection{Model capabilities and limitations}

Transmission losses in an ephemeral channel vary over space and time due to heterogeneous soil characteristics on various surfaces. The capability of the proposed model for accounting for different soil and roughness characteristics in the main channel and the flood plains has been demonstrated through simulations presented in previous section. In fact, consideration of Richards equation was for the purpose of incorporating the longitudinal and transverse variability (spatial) in transmission loss, arising not only due to changes in soil characteristics but also due to differences in the arrival time of the flood waters. Although no simulations are presented, where the longitudinal variation in transmission loss is due to longitudinal variation in soil and roughness characteristics, the model is formulated in such a way that it can easily consider the spatially varying data (through input files for channel and soil characteristics), if they are available. Also, although simulations are not presented for a case where the cross sectional shape varies in the longitudinal direction, the model is capable of taking this into consideration. In this context, it may be noted that the model is conceptualized based on governing equations for flow using flow area, $\mathrm{A}$ and flow rate, $\mathrm{Q}$ as variables, in a conservation form, so that it can handle any cross sectional shape and longitudinal variation in cross sectional shape.

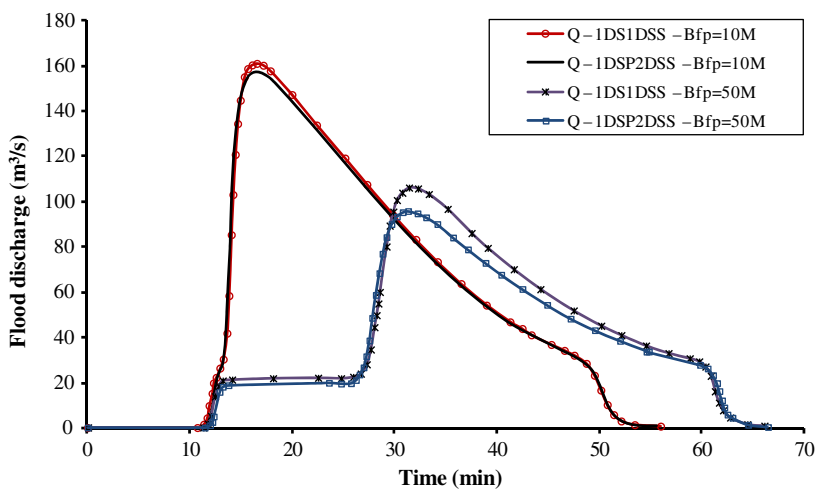

(a)

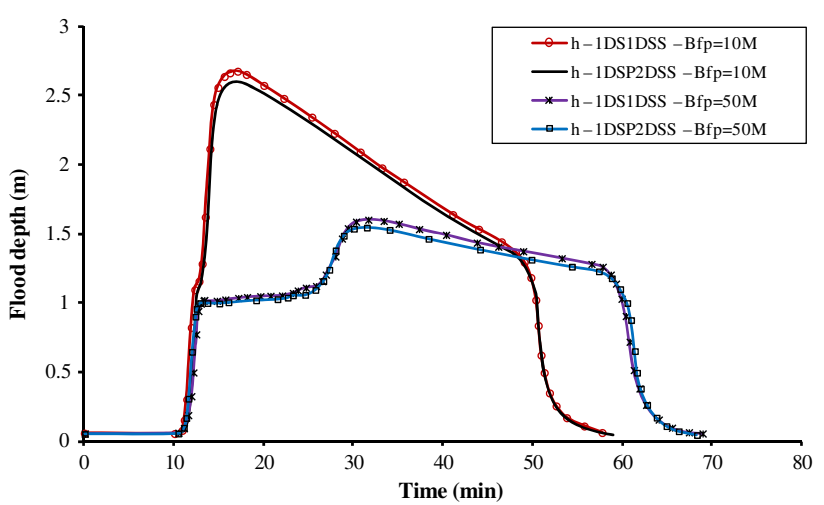

(b)

Figure 13. Comparison of 1DS1DSS and 1DSP2DSS models for Case 7 with clogging layer: (a) Discharge hydrograph; (b) Depth hydrograph.

The present model cannot take into consideration the changes induced to cross-section and bed characteristics due to aggradation and degradation during a flood event. It may be noted that infiltration losses decrease flow depth and sediment transport capacity which cause aggradation in low-gradient channel segments. This in turn may increase the potential for further transmission losses. It may be also noted that high-magnitude floods can completely restructure the ephemeral channel geometry in arid regions [60]. In such cases, there could be temporal variation in infiltration characteristics during the flood event itself and the present model would fail to simulate flood movement correctly. However, such situations are infrequent and in many cases, ephemeral channels tend to maintain similar flow characteristics over long periods of time [61]. Also, the present model can constitute the core hydraulic module in a more elaborate model for simulating flow and geomorphologic changes in ephemeral channels. Such models would necessarily couple a hydraulic model with a model for morphological changes, based on inclusion of equation for conservation of sediment movement.

The computational time step required in the solution of Richards equation is $0.5 \mathrm{~s}$. A small time step is required in order to capture the very high infiltration rate that would 
occur as the wave front reaches a particular location, which is hitherto dry. The computational time taken by the model 1DS1DSS is $1.5 \mathrm{~h}$, while the computational time taken by the model 1DSP2DSS is $11.3 \mathrm{~h}$, on CORE-i7 computer system. Thus the model 1DSP2DSS is computationally more intensive as compared to the model 1DS1DSS. However, the advantage of model 1DSP2DSS is that it can incorporate the lateral variation in transmission losses without having to solve the complete three dimensional Richards equation.

\section{Summary and conclusions}

A mathematical model is presented for flood routing in ephemeral channels with compound cross-sections. Complete Saint Venant equations are numerically solved for simulating the surface flow conditions while the sub-surface flow conditions are simulated by numerically solving the Richards equation for unsaturated conditions. The flood plain and main channel flow interaction is modeled using the interactive divided channel (IDC) method proposed in literature recently. An iterative technique is used for coupling the surface and sub-surface components. The proposed model considers only one dimensional flow in the vertical direction in the soil column. However, it considers different soil columns for main channel and flood plains. This facilitates the consideration of lateral variation in infiltration rate at a cross section, which could arise due to (i) lateral variation in flow depth, (ii) differences in the arrival times of flood wave and (iii) lateral variation in soil characteristics. Simulations have indicated that one can obtain reasonably accurate answers by using the simpler 1DS1DSS model instead of the more elaborate 1DSP2DSS model, if the flood plains are not wide and the channel is not long. However, the transmission losses are either under predicted or over predicted, depending on situation, by as much as $20 \%$, if lateral variation in infiltration rate is not considered for channels with wide flood plains, and when there is a lateral variation in soil characteristics. This can have significant bearing on the management of water resources in arid regions. Limitations of 1DSP2DSS model are (i) it is more data intensive, requiring the data on soil characteristics of the main channel as well as the flood plains, (ii) it is computationally more intensive than the 1DS1DSS model and (iii) it cannot be applied in situations where the flood event induces significant structural changes to the ephemeral channel.

\section{Acknowledgement}

Authors thank Indian Institute of Technology Madras, Chennai, India for providing facilities to carry out this study.

\section{References}

[1] Sorman A U, Mohamed J A and Abdulrazzak M J 1993 Infiltration-recharge through wadi beds in arid regions. Hydrol. Sci. J. 38(3): 173-186. doi:10.1080/02626669309492661

[2] Abdulrazzak M J and Morel-Seytoux H J 1983 Recharge from an ephemeral stream following wetting front arrival to water table. Water Resour. Res. 19(1): 194-200

[3] Goodrich D C 1997 Linearity of basin response as a function of scale in a semiarid watershed. Water Resour. Res. 33(12): 2951-2965

[4] Mansell M G and Hussey S W 2005 An investigation of flows and losses within the alluvial sands of ephemeral rivers in Zimbabwe. J. Hydrol. 314(1-4): 192-203. doi:10.1016/j. jhydrol.2005.03.015

[5] Shentsis I 2003 Increasing transmission losses from flood events due to groundwater extraction. Hydrol. Process. 17(4): 713-725

[6] Cataldo J C, Behr C, Montalto F A, Pierce R J, Eng E, Hall C and Street C 2010 Prediction of transmission losses in ephemeral streams, Western U. S. A. Open Hydrol. J. 4: 19-34

[7] Keppel R V and Renard K G 1962 Transmission losses in ephemeral stream beds. J. Hydraulic Division, ASCE 88 (3): 59-68

[8] Lane L J 1983 Transmission losses in: SCS National Engineering Handbook. US Government Print. Off., Washington, DC. 19-1-19-21

[9] Ponce V M, Pandey R P and Kumar S 1999 Groundwater recharge by channel infiltration in El Barbon basin, Baja California, Mexico. J. Hydrol. 214: 1-7

[10] Goodrich D C, Williams D G and Unkrich C L 2004 Multiple approaches to estimate ephemeral channel recharge. American Geophysical Union, Washington. 77-99. (www. tucson.ars.ag.gov/icrw/Proceedings/Goodrich.pdf)

[11] Shentsis I and Rosenthal E 2003 Recharge of aquifers by flood events in an arid region. Hydrol. Process. 17(4): 695-712.

[12] El-Hames A S and Richards K S 1998 An integrated, physically based model for arid region flash flood prediction capable of simulating dynamic transmission loss. Hydrol. Processes. 12(8): 1219-1232

[13] Hutton C J, Brazier R E, Nicholas A P and Nearing M 2012 On the effects of improved cross-section representation in one-dimensional flow routing models applied to ephemeral rivers. Water Resour. Res. 48(4), n/a-n/a. doi:10.1029/ 2011WR011298

[14] Kollet S J and Maxwell R M 2006 Integrated surfacegroundwater flow modeling: A free-surface overland flow boundary condition in a parallel groundwater flow model. Adv. Water Resour. 29: 945-958

[15] Mudd S M 2006 Investigation of the hydrodynamics of flash floods in ephemeral channels: Scaling analysis and simulation using a shock-capturing flow model incorporating the effects of transmission losses. J. Hydrol. 324: 65-79

[16] Dahan O, Shani Y, Enzel Y, Yechieli Y and Yakirevich A 2007 Direct measurements of floodwater infiltration into shallow alluvial aquifers. J. Hydrol. 344(3-4): 157-170. doi:10.1016/j.jhydrol.2007.06.033 
[17] Dunkerley D and Brown K 1999 Flow behaviour, suspended sediment transport and transmission losses in a small (subbank-full) flow event in an Australian desert stream. Hydrol. Process. 13(11): 1577-1588

[18] Morin E, Grodek T, Dahan O, Benito G, Kulls C, Jacoby Y, Langenhove G V, Seely M and Enzel Y 2009 Flood routing and alluvial aquifer recharge along the ephemeral arid Kuiseb River, Namibia. J. Hydrol. 368(1-4): 262-275

[19] Sharma K D and Murthy J S R 1994 Estimating transmission losses in an arid region-A realistic approach. J. Arid Environ. 27(2): 107-112

[20] Coes A L and Pool D R 2005 Ephemeral-stream channel and basin-floor infiltration and recharge in the Sierra Vista subwatershed of the upper San Pedro basin, Southeastern Arizona, 85. Washington. Retrieved from http://www.usgs. gov/

[21] Parissopoulos G A and Wheater H S 1992 Effects of wadi flood hydrograph characteristics on infiltration. J. Hydrol. 126(3-4): 247-263

[22] Philipp A, Schmitz G H and Liedl R 2010 Analytical model of surge flow in non-prismatic permeable channels and its application in arid regions. J. Hydraul. Eng. 136(5): 290-298

[23] Sorman A U, Abdulrazzak M J and Seytoux M H J 1997 Groundwater recharge estimation from ephemeral streams. case study: Wadi Tabalah, Saudi Arabia. Hydrol. Process. 11: 1607-1619. Retrieved from http://doi.wiley.com/10. 1029/WR014i002p00281

[24] Camporese M, Paniconi C, Putti M and Orlandini S 2010 Surface-subsurface flow modeling with path-based runoff routing, boundary condition-based coupling, and assimilation of multisource observation data. Water Resour. Res. 46(2), n/a-n/a. doi:10.1029/2008WR007536

[25] Costa A C, Foerster S, Araújo J C de and Bronstert A 2013 Analysis of channel transmission losses in a dryland river reach in north-eastern Brazil using streamflow series, groundwater level series and multi-temporal satellite data. Hydrol. Process. 27(7): 1046-1060. doi:10.1002/hyp.9243

[26] Costelloe J F, Grayson R B, Argent R M and McMahon T A 2003 Modeling the flow regime of an arid zone floodplain river, Diamantina River, Australia. Environ. Modell. Software. 18(8-9): 693-703. doi:10.1016/S1364-8152(03)00071-9

[27] Desilets S L E 2007 Flood processes in semi-arid streams: Sediment transport, flood routing, and groundwater-surface water interactions. The University of Arizona

[28] Elfeki A M M, Ewea H A R, Bahrawi J A and Al-Amri N S 2015 Incorporating transmission losses in flash flood routing in ephemeral streams by using the three-parameter Muskingum method. Arab. J. Geosci. doi:10.1007/s12517-0141511-y

[29] Klaus J, Külls C and Dahan O 2008 Evaluating the recharge mechanism of the Lower Kuiseb Dune area using mixing cell modeling and residence time data. J. Hydrol. 358(3-4): 304-316. doi:10.1016/j.jhydrol.2008.06.012

[30] Lange J 2005 Dynamics of transmission losses in a large arid stream channel. J. Hydrol. 306(1-4): 112-126. doi:10.1016/j. jhydrol.2004.09.016

[31] Newman B D, Vivoni E R and Groffman A R 2006 Surface water-groundwater interactions in semiarid drainages of the American southwest. Hydrol. Process. 20(15): 3371-3394. doi:10.1002/hyp.6336
[32] Osterkamp W R, Lane L J and Menges C M 1995 Techniques of ground-water recharge estimates in arid/semi-arid areas, with examples from Abu Dhabi. J. Arid Environ. 31: 349-369

[33] Philipp A and Grundmann J 2013 Integrated modeling system for flash flood routing in ephemeral rivers under the influence of groundwater recharge dams. J. Hydraul. Eng. 139(12): 1234-1246. doi:10.1061/(ASCE)HY.1943-7900. 0000766

[34] Saber M, Hamaguchi T and Kojiri T 2008 Surface runoff modeling of ephemeral streams considering homogenization theory in arid regions, Wadi Assiut in Egypt. Annu. Disaster Prev. Res. Inst. (51B): 769-783. Japan: Kyoto University

[35] Sharma K D and Murthy J S R 1998 A practical approach to rainfall-runoff modelling in arid zone drainage basins. Hydrol. Sci. J. 43(3): 331-348. doi:10.1080/02626669809492130

[36] Walters M O 1990 Transmission losses in arid region. $J$. Hydraul. Eng. 116(1): 129-138. doi:10.1061/(ASCE)07339429(1990)116:1(129)

[37] He Z, Wu W and Wang S S Y 2008 Coupled finite-volume model for 2D surface and 3D subsurface flows. ASCE $J$. Hydrol. Eng. 13: 835-845

[38] Morita M and Yen B C 2002 Modeling of conjunctive two dimensional surface-three-dimensional subsurface flows. $J$. Hydraul. Eng. 128(2): 184-200

[39] Erduran K S 2012 Integrated numerical model for vegetated surface and saturated subsurface flow interaction. Appl. Math. Mech. 33(7): 881-898. doi:10.1007/s10483-012-15929

[40] Ghobadian R and Fathi-Moghadam M 2014 Estimation of seepage losses in ephemeral network and branching streams. J. Hydrol. Eng. 19(2): 299-307. doi:10.1061/(ASCE)HE. 1943-5584.0000788

[41] Cao Z, Meng J, Pender G and Wallis S 2006 Flow resistance and momentum flux in compound open channels. J. Hydraul. Eng. 132(12): 1272-1282. doi:10.1061/(ASCE)0733-9429.

[42] Vyverberg K 2010 A review of stream processes and forms in dry land watersheds. Report submitted to California Department of Fish and Game. 1-36

[43] Yen O C 2002 Open channel flow resistance. J. Hydraul. Eng. 128(1): 20-39

[44] Bousmar D and Zech Y 1999 Momentum transfer for practical flow computation in compound channels. J. Hydraul. Eng. 125(7): 696-706

[45] Costabile P and Macchione F 2012 Analysis of one-dimensional modelling for flood routing in compound channels. Water Resour. Manag. 26: 1065-1087

[46] Helmio T 2002 Unsteady 1D flow model of compound channel with vegetated floodplains. J. Hydraul. 269: 89-99

[47] Huthoff F, Roos P C, Augustijn D C M and Hulscher S J M H 2009 Interacting divided channel method for compound channel flow. J. Hydraul. Eng. 134(8): 1158-1165

[48] Rashid R S M and Chaudhry H M 1995 Flood routing in channels with flood plains. J. Hydrol. 171(1-2): 75-91. doi:10.1016/0022-1694(95)02693-J

[49] Yoshida H and Dittrich A 2002 1D unsteady-state flow simulation of a section of the upper Rhine. J. Hydrol. 269: 79-88

[50] Freeze R A and Cherry J A 1979 Groundwater, PrenticeHall, Englewood Cliffs, NJ 
[51] Van Genuchten M T 1980 A closed form equation for predicting the hydraulic conductivities of unsaturated soils. Soil Sci. Soc. Am. J. 44: 892-898

[52] Nujic M 1995 Efficient implementation of non-oscillatory schemes for the computation of free-surface flows. $J$. Hydraul. Res. IAHR 33(1): 101-111

[53] Singh V and Bhallamudi S M 1998 Conjunctive surfacesubsurface modeling of overland flow. Adv. Water Resour. 21: $567-579$

[54] Yee H C 1989 A class of high resolution explicit and implicit shock-capturing methods, NASA Technical Memorandum 101088, Ames Research Center, CA

[55] Garcia-Navarro P, Hubbard M E and Priestley A 1995 Genuinely multidimensional upwinding for the 2D shallow water equations. J. Comput. Phys. 121(1): 79-93

[56] Chaudhry M H 2008 Open-channel flow. 2nd ed. New York: Springer; 2008. xvi, $523 \mathrm{p}$
[57] Hong L D, Akiyama and Ura M 1994 Efficient mass conservative numerical solution for the two-dimensional unsaturated flow equation. J. Hydrosci. Hydraul. Eng. 11(2): 1-18

[58] Panday S and Huyakorn P S 2004 A fully coupled physically-based spatially-distributed model for evaluating surface/subsurface flow. Adv. Water Resour. 27(4): 361-382

[59] Lai C J, Liu C L and Lin Y Z 2000 Experiments on flood wave propagation in compound channel. J. Hydraul. Eng. 126: 492-501

[60] Sutfin N A, Shaw J R, Wohl E E and Cooper D J 2014 A geomorphic classification of ephemeral channels in a mountainous, arid region, South Western Arizona, USA. Geomorphology 221: 164-175

[61] Bull L J and Kirkby M J 2002 Dryland river characteristics and concepts. In: Bull L J and Kirkby M J (Eds.) Dryland rivers: Hydrology and geomorphology of semi-arid channels. John Wiley and Sons, Chichester, pp. 3-15 